\title{
Level of Glycemic Control and Its Associated Factors among Type II Diabetic Patients in Debre Tabor General Hospital, Northwest Ethiopia
}

Journal of Diabetes and Endocrinology Research

Research Article

Alemayehu Digssie ${ }^{1 *}$, Sofonyas Abebaw Tiruneh ${ }^{1}$, Asnakew Achaw Ayele ${ }^{3}$, Henok Getachew Tegegn $^{3,4}$, Belete Achamyelew Ayele ${ }^{2}$ and Melaku Tadege ${ }^{1}$

\author{
${ }^{1}$ Social and Public Health Unit, College of Health Sciences, \\ Debre Tabor University. \\ ${ }^{2}$ Department of Epidemiology and Biostatics, Institute of Public \\ health College of Medicine and Health Science, University of \\ Gondar, Ethiopia \\ ${ }^{3}$ Department of Clinical Pharmacy, School of Pharmacy, \\ College of Medicine and Health Science, University of Gondar, \\ Ethiopia \\ ${ }^{4}$ School of Medicine and Pharmacy, University of New England, \\ Armidale, NSW 2351, Australia
}

\author{
*Correspondence author \\ Alemayehu Digssie \\ Department of Public Health \\ College of Health Sciences \\ Debre Tabor University \\ Debre Tabor \\ Ethiopia \\ E-mail :metsagu@yahoo.com
}

Submitted : 6 March 2020 ; Published : 26 March 2020

\begin{abstract}
Introduction: Poor glycemic control is the major risk factor for the development of acute and chronic diabetes complications. There are limited studies on the level of glycemic control among diabetes and its associated factors. So, the aim of this study was to assess the level of glycemic control and its associated factors among type II DMpatients in Debre Tabor General Hospital.

Methods: An institution based cross-sectional study was conducted from November 1-30, 2017 on 413 diabetic patients who were selected by systematic random sampling. The three months average fasting blood glucose was used to determine glycemic control. Regressions were fitted to identify associated factors. P-value $<0.05$ was used to declare statistical significance.

Results: A total of 398 study participants were participated in the study with a response rate of 96.4\%. Among 398 type II DM patients, 284 (71.4\%) had poor glycemic control. patient's educational status (AOR=3.0, 95\%CI (1.5, 5.7), (AOR= 4.5, 95\%CI $(1.8,10.9)$, and $(A O R=5.7,95 \% C I(2.9,11.2))))$, family history of $D M(A O R=2.3,95 \% C I(1.4,3.9))$, Duration of DM since diagnosis $(A O R=0.3,95 \% C I(0.1,0.9))$, and Dietary adherence $(A O R=2.4,95 \% C I(1.4,4.1))$ were associated factors of glycemic control.

Conclusion: Poor glycemic control was high. Educational status, family history of DM, duration of DM, and dietary adherence were independent predictors of glycemic control. Appropriate attention should be given for glycemic control especially for patients with a longer duration. Health promotion should be cross-cutting intervention for DM patients about medical recommendations.
\end{abstract}

\section{Keywords: Type II DM, Glycemic control, Fasting blood glucose, Debre Tabor General Hospital}

\section{Introduction}

Non-communicable diseases are becoming major problems of public health importance in most developing countries as a result of the effects of global-Imation and epidemiologic transition Non-communicable diseases are becoming major problems of public health importance in most developing countries as a result of the effects of global-Imation and epidemiologic transition Non-communicable diseases are becoming major problems of public health importance in most developing countries as a result of the effects of global- Imation and epidemiologic transition Non-communicable diseases are becoming major problems of public health importance in most developing countries as a result of the effects of global-ization and epidemiologic transition Non-communicable diseases are becoming major problems of public health importance in most developing countries as a result of the effects of global-ization and epidemiologic transition Non-communicable diseases are becoming major problems of public health importance in most developing countries as a result of the effects of global-ization and epidemiologic transition. 
Diabetics Mellitus is a raised level of glucose in the blood due to either the body cannot produce enough amount of insulin hormone or use insulin effectively [1]. The global prevalence and impact of diabetes mellitus has increased dramatically, particularly in sub-Saharan Africa and it is one of the major public health problem in developing countries due to the most rapid epidemiological transitions [2-5].

In 2012 diabetes mellitus, caused 1.5 million deaths worldwide among this $43 \%$ befall before the age of 70 years [1]. Globally it is estimated that 425 million people live with diabetes aged $20-79$ years, $90 \%$ of whom accounts type 2 diabetes mellitus, and it will raise 642 million by 2040 [6-8].The prevalence of diabetes in Africa has raised from 4 million in 1980 to 25 million in 2014 , which increased by $129 \%$ (3.1\% in 1980 to $7.1 \%$ in 2014)and Ethiopia accounts $3.8 \%$, and $9 \%$ in gestational diabetes mellitus [9]. In sub-Saharan Africa, 90\% of people living with type 2 diabetes mellitus typically associated with increasing age and obesity $[9,10]$.

Diabetics Mellitus has a wide range of medical complication such as retinopathy, neuropathy, micro albuminuria, and it increases the risk of numerous infectious disease including tuberculosis, pneumonia, and sepsis particularly in SubSaharan Africa [9]. Glycemic control remains the major focus for the management of type 2 diabetes mellitus [11]. Poor glycemic control among type 2 diabetes mellitus patients constitutes a major public health problem and a risk factor for the development of acute and chronic diabetes complications [12-14].Studies evidenced thatgood glycemic control reduces the risk of diabetic related complications and death $[15,16]$.

Despite, of the importance of good glycemic control evidence showed that there is poor glycemic control in Ethiopia [1720]. Different studies evidenced that being unable to read and write, farmer, having poor medication adherence, duration with diabetics, and duration of diabetics treatment were the significant associated factors for poor glycemic control among type 2 diabetic patients [12, 20-22]. The aim of this study was to assess the level of glycemic control and its associated factors among type 2 diabetic patients attending their follow up at Debre Tabor General Hospital, Northwest Ethiopia.

\section{Methods and Participants}

\section{Study Design, Area and Period}

Institutional based cross-sectional study design was conducted from November01/2017- November 30/2017 at Debre Tabor General Hospital. Debre Tabor General Hospital is found in Debre Tabor Town, South Gondar Zone of Amhara Regional state that is about 667 kilometers far from the capital city of Ethiopia in Northwest direction and 102 kilometers far from Bahir Dar town.

A total of 413 study participants were included. The sample size was calculated by using single population proportion formula considering the prevalence of poor glycemic control is $57.5 \%$ among type 2 diabetic patients from previous study done in Ethiopia, 95\% confidence level and 5\% of marginal error by adding none response rate of $10 \%$. Systematic random sampling technique was employed to select the study participants. A total of 850 type 2 diabetic patients had follow up at Debre Tabor General Hospital, and then we calculate the Kth interval that was 2 . So, we interview the study participants every 2 type 2 diabetic patients [23]. All type 2 diabetic patients aged $\geq 18$ years who had at least one-year outpatient follow up at Debre Tabor General Hospital were included in the study, whereas newly diagnosed type 2 diabetic patients, critically ill and unable to speak and hear at the time of data collection were excluded from the study.

\section{Data Collection}

The data was collected by two trained nurses by face-to-face interview by using pre-tested and structured questionnaire. Patient chart review was carried out to determine of threemonth average Fast Blood Sugar (FBS) and diabetics related complications. The dietary adherence status was assessed by Perceived Dietary Adherence Questionnaire (PDAQ), and diabetic related knowledge assessed by Diabetes Knowledge Test (DKT) questionnaire [24-26].

\section{Data processing and analysis:}

The collected data were entered into EpiData version 3.1 and double entry was made. The entered data were exported to Statistical Package for Social Science (SPSS) version 20 software for analysis. Descriptive statistics was employed for sociodemographic characteristics of the respondents. Bivariate and multivariable logistic regression was done to identify independent factors of glycemic control. P-value less than 0.2 was used to select candidate variables for multivariable logistic regression. Hosmer and Lemeshow's goodness-offit test was used to check the data is appropriate for multiple logistic regression model. Crude Odds Ratio (COR), Adjusted Odds Ratio(AOR) with $95 \% \mathrm{CI}$ were employed to determine the associated factor of type 2 diabetic patient glycemic control and P- value less or 0.05 was considered as statically significant.

\section{Operational Definitions}

Good glycemic control was defined as an average of three consecutive fasting blood glucose measurement $80-130 \mathrm{mg} /$ dl. Poor glycemic control was defined as patients who's had average blood glucose measurements on three consecutive visits $>130$ or $<70 \mathrm{mg} / \mathrm{dl}$ [27]. The Perceived Dietary Adherence Questionnaire (PDAQ) is 9-item seven-point Likert scale questionnaires assessing the dietary adherence status of the last seven days. PDAQ has a total of 63 scores for 9-item questions, and for each item, a higher score reflects higher dietary adherence except item 4 and 9 , which is reversely coded. To declare good dietary adherence having a total sum scores of $\geq 31.5$ scores. Diabetes Knowledge Test (DKT) questionnaire has a 23 -item multiple-choice questions. Item 1-14 designed for all adult diabetic patients. The DKT score 
was determined by dividing the number of correct answers by the total number of questions (14 for those receiving oral hypoglycemic agents). Scores having $\geq 75 \%, 74-60 \%$ and $\leq 59 \%$, were used to declare good, medium and poor diabetic related knowledge respectively. Respondents having good and medium diabetic related knowledge were merged in to good diabetic related knowledge $[28,29]$.

\section{Ethical Consideration:}

The study was conducted after getting ethical clearance letter from Debre Tabor University College of Health Sciences. The data were collected after obtaining permission from Debre Tabor General Hospital medical director and chief executive director. Informed consent was obtained from each study participants. The name of the study participants was not registered for the assurance of confidentiality and social desirability bias. Individuals are informed that they could withdraw at the time of interview.

\section{Results}

Socio-demographic and Clinical Characteristics of the respondents:

A total of 398 study participants were participated in the study with a response rate of $96.4 \%$. Majority of the study participants were males $211(53 \%)$. The mean $( \pm \mathrm{SD})$ age of patients with type 2 diabetes was $52.63( \pm 12.34)$ years. Most of the respondents were orthodox 357 (89.7\%) in religion and $283(71.1 \%)$ of the study participants had family history of diabetes mellitus (Table 1).

\begin{tabular}{|c|c|c|c|}
\hline & Variables & Frequency & Percent (\%) \\
\hline \multirow[t]{2}{*}{ Sex } & Male & 211 & 53.0 \\
\hline & Female & 187 & 47.0 \\
\hline \multirow[t]{4}{*}{ Age } & $18-34$ years & 10 & 2.5 \\
\hline & $35-50$ years & 189 & 47.5 \\
\hline & $51-64$ years & 128 & 32.2 \\
\hline & $\geq 65$ years & 71 & 17.8 \\
\hline \multirow[t]{4}{*}{ Marital Status } & Single & 44 & 11.1 \\
\hline & Married & 272 & 68.3 \\
\hline & Divorced & 71 & 17.8 \\
\hline & Separated & 11 & 2.8 \\
\hline \multirow[t]{3}{*}{ Religion } & Orthodox & 357 & 89.7 \\
\hline & Protestant & 7 & 1.8 \\
\hline & Muslim & 34 & 8.5 \\
\hline \multirow[t]{2}{*}{ Residence } & Urban & 234 & 58.8 \\
\hline & Rural & 164 & 41.2 \\
\hline
\end{tabular}

\begin{tabular}{|c|c|c|c|}
\hline \multirow[t]{5}{*}{$\begin{array}{l}\text { Educational } \\
\text { Status }\end{array}$} & $\begin{array}{l}\text { Unable to read } \\
\text { and write }\end{array}$ & 177 & 44.5 \\
\hline & $\begin{array}{l}\text { Able to read } \\
\text { and write }\end{array}$ & 75 & 18.8 \\
\hline & $\begin{array}{l}\text { Primary } \\
\text { Education }\end{array}$ & 30 & 7.5 \\
\hline & $\begin{array}{l}\text { Secondary } \\
\text { Education }\end{array}$ & 45 & 11.3 \\
\hline & $\begin{array}{l}\text { Higher } \\
\text { Education and } \\
\text { above }\end{array}$ & 71 & 17.8 \\
\hline \multirow[t]{5}{*}{$\begin{array}{l}\text { Occupational } \\
\text { Status }\end{array}$} & \begin{tabular}{|l} 
Government \\
Employee
\end{tabular} & 89 & 22.4 \\
\hline & Merchant & 74 & 18.6 \\
\hline & Farmer & 142 & 35.7 \\
\hline & NGO & 34 & 8.5 \\
\hline & House Wife & 59 & 14.8 \\
\hline \multirow{2}{*}{$\begin{array}{l}\text { Family history } \\
\text { of DM }\end{array}$} & No & 283 & 71.1 \\
\hline & Yes & 115 & 28.9 \\
\hline \multirow{2}{*}{$\begin{array}{l}\text { Distance from } \\
\text { the Hospital }\end{array}$} & $\leq 30$ minutes & 144 & 36.2 \\
\hline & $>30$ minutes & 254 & 63.8 \\
\hline \multirow[t]{2}{*}{ Smoking } & Yes & 16 & 4.0 \\
\hline & No & 382 & 96.0 \\
\hline
\end{tabular}

Table 1: Socio-demographic Characteristics of Patients with Type 2 Diabetes Mellitus Attending their Follow up at Diabetic Clinic of Debre Tabor General Hospital, Ethiopia, 2017. $(\mathrm{n}=398)$

Level of glycemic Control and Clinical Characteristics of the Respondents:

Out of 398 study participants, $71.4 \%$ had poor glycemic control. The mean $( \pm \mathrm{SD})$ of fasting blood glucose was 175.52 $( \pm 69.34) \mathrm{mg} / \mathrm{dl}$ with inter quartile range of (213- 124). The mean duration of DM since diagnosis with diabetes mellitus and starting of treatment was 5.32 and 5.18 years respectively. Among the total of respondents having glucometer at home $(34.9 \%)$ had good glycemic control compered to not having glucometer at home which is $26.9 \%$ (Table 2). 


\begin{tabular}{|c|c|c|c|c|c|c|}
\hline & \multirow[t]{2}{*}{ Variables } & \multicolumn{5}{|c|}{ Glycemic Control Level } \\
\hline & & Poor & $\mathrm{N}(\%)$ & Good & $\mathrm{N}(\%)$ & Total N \\
\hline \multirow[t]{2}{*}{ Sex } & Male & 146 & $(69.2)$ & 65 & $(30.8)$ & 211 \\
\hline & Female & 138 & $(73.8)$ & 49 & $(26.2)$ & 187 \\
\hline \multirow[t]{2}{*}{ Resident } & Urban & 157 & $(67.1)$ & 77 & $(32.9)$ & 234 \\
\hline & Rural & 127 & $(77.4)$ & 37 & $(22.6)$ & 164 \\
\hline \multirow[t]{3}{*}{ Duration of DM Treatment } & $1-5$ years & 161 & $(65.2)$ & 86 & $(34.8)$ & 247 \\
\hline & 6-10 years & 90 & $(78.9)$ & 24 & $(21.1)$ & 114 \\
\hline & $>10$ years & 33 & $(89.2)$ & 4 & $(10.8)$ & 37 \\
\hline \multirow{2}{*}{$\begin{array}{l}\text { Number of medication taken per } \\
\text { day }\end{array}$} & One & 69 & $(59.5)$ & 47 & $(40.5)$ & 116 \\
\hline & Two and above & 215 & $(76.2)$ & 67 & $(23.8)$ & 282 \\
\hline \multirow[t]{2}{*}{ Having glucometer at home } & No & 228 & $(73.1)$ & 84 & $(26.9)$ & 312 \\
\hline & Yes & 56 & $(65.1)$ & 30 & $(34.9)$ & 86 \\
\hline \multirow[t]{2}{*}{ Chronic illness } & No & 178 & $(73.9)$ & 63 & $(26.1)$ & 241 \\
\hline & Yes & 106 & $(67.5)$ & 51 & $(32.5)$ & 157 \\
\hline \multirow[t]{2}{*}{ Dietary adherence status } & Poor Adherence & 99 & $(78 .-6)$ & 27 & $(21.4)$ & 126 \\
\hline & Good Adherence & 185 & $(68.0)$ & 87 & $(32.0)$ & 272 \\
\hline
\end{tabular}

Table 2: Socio-demographic and clinical characteristics of patients with type 2 diabetes mellitus patients attending their follow up at diabetic clinic of Debre Tabor General Hospital, Ethiopia, 2017. (n=398)

Factors associated with glycemic control

In bivariate logistic regression, age of the patient, marital status, residence, educational status, family history of DM, duration of DM since diagnosis, ever had diabetic education, and dietary adherence were significantly associated factors with glycemic control among type II DM patients. In multivariable logistic regression, patient's educational status, family history of DM, Duration of DMsince diagnosis, and Dietary adherence were significantly associated with glycemic control among type II diabetic patients.

Diabetic patients who can read and write are 3 times more likely to have good glycemic control as compared with those who couldn't read and write $(\mathrm{AOR}=3.0,95 \% \mathrm{CI}(1.5,5.7))$. Type II Diabetic patients who learnt up to primary educational level are 4 times more likely to have good glycemic control as compared with those who couldn't read and write $(\mathrm{AOR}=4.5,95 \% \mathrm{CI}$ $(1.8,10.9))$. Diabetic patients who achieve college and above educational status are 5.7 times more likely to have good glycemic control as compared with those who couldn't read and write ( $\mathrm{AOR}=5.7,95 \% \mathrm{CI}(2.9,11.2)$ ).

Type II diabetic patients who have family history of diabetes mellitus are 2.1 times more likely to have good glycemic control as compared with those who didn't have family history of diabetes mellitus ( $\mathrm{AOR}=2.3,95 \% \mathrm{CI}(1.4,3.9)$ ). Type II diabetic patients with greater than 10 years duration since diagnosis are $70 \%$ less likely to have good glycemic control as compared with those with less than 5 years duration of diabetes mellitus since diagnosis (AOR $=0.3,95 \% \mathrm{CI}(0.1,0.9))$.

Diabetic patients who have good dietary adherence are 2.4 times more likely to have good glycemic control as compared with those who have poor dietary adherence $(\mathrm{AOR}=2.4,95 \% \mathrm{CI}(1.4,4.1))$. (Table 3$)$ 


\begin{tabular}{|c|c|c|c|c|c|}
\hline Variables & & Poor Glycemic Control & Good Glycemic Control & COR $(95 \% \mathrm{CI})$ & AOR $(95 \% \mathrm{CI})$ \\
\hline \multirow[t]{4}{*}{ Age of the patient } & $18-34$ years & 3 & 7 & $7.4(1.7,31.9)$ & \\
\hline & $35-50$ years & 128 & 61 & $1.5(0.8,2.8)$ & 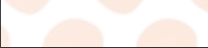 \\
\hline & 51-64 years & 99 & 29 & $0.9(0.5,1.8)$ & 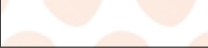 \\
\hline & Above 65 years & 54 & 17 & 1 & 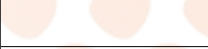 \\
\hline \multirow[t]{4}{*}{ Marital status } & Single & 22 & 22 & 1 & \\
\hline & Married & 197 & 73 & $0.4(0.2-0.7)$ & \\
\hline & Divorced & 56 & 15 & $0.3(0.1-0.6)$ & 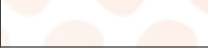 \\
\hline & Separated & 7 & 4 & $0.6(0.1-2.2)$ & \\
\hline \multirow[t]{2}{*}{ Residence } & Urban & 157 & 77 & 1 & \\
\hline & Rural & 127 & 37 & $0.6(0.4-0.9)$ & \\
\hline \multirow[t]{5}{*}{ Educational Status } & $\begin{array}{l}\text { Un able to read } \\
\text { and write }\end{array}$ & 149 & 27 & 1 & 1 \\
\hline & $\begin{array}{l}\text { Able to read and } \\
\text { write }\end{array}$ & 50 & 25 & $2.6(1.4,5.0)$ & $3.0(1.5,5.7)$ \\
\hline & $\begin{array}{l}\text { Primary } \\
\text { Education }\end{array}$ & 17 & 13 & $4.1(1.8,9.3)$ & $4.5(1.8,10.9)$ \\
\hline & $\begin{array}{l}\text { Secondary } \\
\text { Education }\end{array}$ & 34 & 11 & $1.7(0.8,3.8)$ & $2.2(1.0,5.0)$ \\
\hline & College and above & 34 & 37 & $5.8(3.1,10.7)$ & $5.7(2.9,11.2)$ \\
\hline \multirow{2}{*}{$\begin{array}{l}\text { Family history of } \\
\text { DM }\end{array}$} & No & 215 & 68 & 1 & 1 \\
\hline & Yes & 69 & 46 & $2.1(1.3,3.3)$ & $2.3(1.4,3.9)$ \\
\hline \multirow{3}{*}{$\begin{array}{l}\text { Duration of DM } \\
\text { since diagnosis }\end{array}$} & Less than 5 years & 155 & 86 & 1 & 1 \\
\hline & 5- 10 years & 89 & 24 & $0.5(0.3,0.5)$ & $0.6(0.3,1.0)$ \\
\hline & $\begin{array}{l}\text { Greater than } 10 \\
\text { years }\end{array}$ & 40 & 4 & $0.2(0.1,0.5)$ & $0.3(0.1,0.9)$ \\
\hline \multirow{2}{*}{$\begin{array}{l}\text { Ever had Diabetic } \\
\text { Education }\end{array}$} & No & 44 & 240 & 1 & \\
\hline & Yes & 10 & 104 & $2(0.9,3.9)$ & \\
\hline \multirow[t]{2}{*}{ Dietary adherence } & Poor & 99 & 27 & 1 & 1 \\
\hline & Good & 185 & 87 & $1.7(1.1,2.8)$ & $2.4(1.4,4.1)$ \\
\hline
\end{tabular}

Table 3: Factors associated with glycemic control among type 2 diabetes mellitus patients attending their follow up at diabetic clinic of Debre Tabor General Hospital, Ethiopia, 2017. $(\mathrm{n}=398)$

\section{Discussion}

Chronic non communicable diseases are becoming the problems of low and middle income countries including Ethiopia due to numerous reasons. Diabetes contributes the greatest line share of chronic non communicable diseases. Glycemic control is the most important diabetes care and management for diabetic patients. Poor glycemic control is a major health problem which greatly contributes for the development of diabetesrelated complications.

The result of this study showed that the level of glycemic control among type II diabetic patients is $71.4 \%$ which is consistent with the study done at Dessie Referral hospital (70.8\%), Jimma University teaching Hospital (70.9\%), Turkey (67.5), Myanmar (72.1\%), and Saudi Arabia (74.9\%)(12,20,30-32). Whereas it is below than the study conducted at TikurAnbessa hospital (80\%), South Africa (83.8\%), Kenya (81.6\%), India $(91.8 \%)$ and Palestine $(80.5 \%)(33-37)$. On the other hand, it is higher than the study done at Zambia (61.3\%), Limmu Genet Hospital (63.8\%), Suhul Hospital (63.5\%), Nigeria
(55\%), Ayider Specialized hospital (48.7\%) and Shenen Gibe Hospital $(59.2 \%)(21,38-42)$. The possible justification for the discrepancy might be the difference in quality of care given for the patients in different hospitals that studies were conducted and the method used to assess the glycemic level.

The result of our study revealed that educational status of type II diabetic patients had significant association with glycemic control. Diabetic patients who can read and write, learnt primary school and achieve college and above educational status are 3, 4 and 5.7 times more likely to have good glycemic control as compared with those who couldn't read and write respectively. This is consistent with study conducted at Dessie Referral Hospital, Jimma University Teaching Hospital and Shenen Gibie Hospital [20, 21, 30-39]. The reason might be educational status may affect patients adherence to medical recommendations.

This study indicated that family history of diabetes mellitus had associated with glycemic control of diabetes mellitus. Type II diabetic patients who have family history of diabetes mellitus 
are 2.1 times more likely to have good glycemic control. This finding is similar with the study conducted at Saudi Arabia [32]. The probable reason might be diabetes patients with family history of diabetes mellitus may have better information about medical recommendations for diabetes patients.

Our study showed that duration of diabetes since diagnosis had significant association with glycemic control of type II diabetes patients. Type II diabetic patients with greater than 10 years duration since diagnosis are 70\% less likely to have good glycemic control as compared with those with less than 5 years duration of diabetes mellitus since diagnosis. This is in line with studies done at Tikur Anbessa Hospital, Dessie Referral Hospital, South Africa, Limmu Genet Hospital, Malaysia, Ayider Referral Hospital, Palestine, Jordan, and SaudiArabia $[30,32,33,37,39,40-43]$. The possible justification may as the duration increases the ability to secret insulin will decrease in type II diabetes mellitus and age by itself may be contribution.

The result of this study revealed that adherence to dietary recommendation had significant associated with glycemic control among type II diabetes patients. Diabetic patients who have good dietary adherence are 2.4 times more likely to have good glycemic control as compared with those who have poor dietary adherence. This finding is consistent with the study conducted at Suluh Hospital and India $[18,36]$.

\section{Conclusion and recommendations}

Level of glycemic control among type II diabetes patients were poor. Educational status, having family history of DM, duration of DM since diagnosis and dietary adherence to dietary recommendations were independent predictors of glycemic control among type II DM patients.

During diabetes patient follow up, clinicians should give appropriate attention for glycemic control since it is the main goal of diabetes management. Special attention should be given for DM patients with longer duration. Health professionals shall put their effort on evidence generation, health promotion and awareness creation about diabetes mellitus and its control. Data Availability

We have the data of this research article and can provide it as per the request.

Competing Interests

We declare that we have no competing interests.

Funding Statement

We didn't receive any kind of fund for this research.

\section{Authors' Contributions}

All stated authors AD, SA, AA, HG, BA, and MT are involved in the study from the inception to design, acquisition of data, analysis and interpretation and drafting of the manuscript. All authors read and approved the final manuscript.

\section{References}

1. World Health Organization (2016) Global Report on Diabetes.

2. Pastakia SD, Pekny CR, Manyara SM, Fischer L (2017)
Diabetes in sub-Saharan Africa - from policy to practice to progress: Targeting the existing gaps for future care for diabetes. Diabetes, Metabolic Syndrome and Obesity 10: 247-263.

3. Assah F, Mbanya JC (2016) Diabetes in sub-saharan Africa. Diabetes Mellit Dev Ctries Underserved Communities. Elsevier Ltd 375: 33-48.

4. Nigatu $T$ (2012) Epidemiology, complications and management of diabetes in Ethiopia: A systematic review. J Diabetes 4: 174-180.

5. Animaw W, Seyoum Y (2017) Increasing prevalence of diabetes mellitus in a developing country and its related factors. PLoS One 12: 1-11.

6. Zheng Y, Ley SH, Hu FB (2017) Global aetiology and epidemiology of type 2 diabetes mellitus and its complications. Nat Rev Endocrinol 14: 88-89.

7. Ogurtsova K, da Rocha Fernandes JD, Huang Y, Linnenkamp U, Guariguata L, et al. (2017) IDF Diabetes Atlas: Global estimates for the prevalence of diabetes for 2015 and 2040. Diabetes Res Clin Pract. Elsevier BV 128: 40-50.

8. Hall Victoria, Thomsen Reimar, Henriksen Ole, Lohse Nicolai (2011) Diabetes in Sub Saharan Africa 1999-2011: Epidemiology and public health implications. a systematic review. BMC Public Health 11: 1-26.

9. Atun R, Davies JI, Gale EAM, Bärnighausen T, Beran D, et al. (2017) Diabetes in sub-Saharan Africa: from clinical care to health policy. Lancet Diabetes Endocrinol 5: 622667.

10. Inzucchi SE, Bergenstal RM, Buse JB, Diamant $M$, Ferrannini E, et al. (2015) Management of Hyperglycemia in Type 2 Diabetes, 2015: A Patient-Centered Approach: Update to a position statement of the american diabetes association and the european association for the study of diabetes. Diabetes Care 38: 140-149.

11. Kayar Y, Ilhan A, Kayar NB, Unver N, Coban G, et al. (2017) Relationship between the poor glycemic control and risk factors, life style and complications. Biomed Res 28: 1581-1586.

12. Bash LD, Selvin E, Steffes M, Coresh J, Astor BC (2008) Poor Glycemic Control in Diabetes and the Risk of Incident Chronic Kidney Disease Even in the Absence of Albuminuria and Retinopathy. Arch Intern Med 168: 2440 .

13. Koro CE, Bowlin SJ, Bourgeois N, Fedder DO (2004) Glycemic Control From 1988 to 2000 Among U.S. Adults Diagnosed With Type 2 Diabetes. Diabetes Care 27: 1720.

14. Turner R (1998) Effect of intensive blood-glucose control with metformin on complications in overweight patients with type 2 diabetes (UKPDS 34). Lancet 352: 854-865.

15. Group UPDS (UKPDS) (1998) blood-glucose control with sulphonylureas or insulin compared with conventional treatment and risk of complications in patients with type 2 diabetes (UKPDS 33). Lancet 352: 837-853.

16. Angamo MT, Melese BH, Ayen WY (2013) Determinants of Glycemic Control among Insulin Treated Diabetic Patients in Southwest Ethiopia: Hospital Based Cross 
Sectional Study. PLoS One 8: e61759.

17. Fseha B (2017) Glycemic Control and it's Associated Factors in Type 2 Diabetic Patients in Suhul Hospital, Northwest Tigray, Ethiopia. J Diabetes Metab 8: 729.

18. Alebachew Woldu M, Diriba Wami C (2014) Factors Associated with Poor Glycemic Control among Patients with Type 2 Diabetes Mellitus in Ambo Hospital, Ambo; Ethiopia. Endocrinol Metab Syndr 3: 1-6.

19. Kassahun T, Eshetie T, Gesesew H (2016) Factors associated with glycemic control among adult patients with type 2 diabetes mellitus: a cross-sectional survey in Ethiopia. BMC Res Notes. BioMed Central 9: 78.

20. Yigazu DM, Desse TA (2017) Glycemic control and associated factors among type 2 diabetic patients at Shanan Gibe Hospital, Southwest Ethiopia. BMC Res Notes 10: 13-20.

21. Gisela Kobelt, Jennifer Eriksson GP (2017) The burden of multiple sclerosis 2015: Methods of data collection, assessment and analysis of costs, quality of life and symptoms. Mult Scler J 23: 153-156.

22. Alemu, Solomon, Mekonnen Abebe, Yemane Berhane, Alemayehu Worku S, Nebiyu (2015) Level of sustained glycemic control and associated factors among patients with diabetes mellitus in Ethiopia : a hospital-based crosssectional study. Diabetes, Metab Syndr Obes Targets Ther 8: 65-71.

23. Tandon S, Chew M, Eklu-gadegbeku CK, Shermock KM, Morisky DE (2015) Validation and psychometric properties of the 8-item Morisky Medication Adherence Scale ( MMAS-8 ) in Type 2 diabetes patients in subSaharan Africa. Diabetes Res Clin Pract 110: 129-36.

24. Ghada Asaad, Maryam Sadegian, Rita Lau, Yunke Xu, Diana C (2015) Soria-Contreras RCB and CBC. The Reliability and Validity of the Perceived Dietary Adherence Questionnaire for People with Type 2 Diabetes. Nutrients 7: 5484-5496.

25. Fitzgerald JT, Funnell MM, Anderson RM, Nwankwo R, Stansfield RB, et al. (2016) Validation of the Revised Brief Diabetes Knowledge Test (DKT2). Diabetes Educ 42: 178-187.

26. American Diabetes Association (ADA) (2017) Standard of medical care in diabetes - 2017. Diabetes Care 40: s4128.

27. Ali M, Alemu T, Sada O (2017) Medication adherence and its associated factors among diabetic patients at zewditu memorial hospital, addis ababa, ethiopia. BMC Res Notes. BioMed Central 10: 1-5.

28. Kassahun T, Gesesew H, Mwanri L, Eshetie T (2016) Diabetes related knowledge, self-care behaviours and adherence to medications among diabetic patients in Southwest Ethiopia: A cross-sectional survey. BMC Endocr Disord. BMC Endocrine Disorders 16: 28.

29. Fiseha T, Alemayehu E, Kassahun W, Adamu A, Gebreweld A (2018) Factors associated with glycemic control among diabetic adult out-patients in Northeast Ethiopia. BMC Res Notes [Internet]. BioMed Central 11: 4-9.

30. Wynn Nyunt Sandhi (2010) Self-Efficacy, Self-Care Behaviors and Glycemic Control Among Type-2.
Southeast Asian J Trop Med Public Health 41: 943-951.

31. Alzaheb RA, Altemani AH (2018) The prevalence and determinants of poor glycemic control among adults with type 2 diabetes mellitus in Saudi Arabia. Diabetes, Metab Syndr Obes Targets Ther 11: 15-21.

32. Anbessa T, Hospital S, Ababa A (2015) Assessment of the Magnitude of Glycemic Control and Its Associated Factors Among Patients With Type 2 Diabetes At. PLoS One 2015: 1-76.

33. Adeniyi OV, Yogeswaran P, Longo-Mbenza B, Goon D Ter, Ajayi AI (2016) Cross-sectional study of patients with type 2 diabetes in or Tambo district, South Africa. BMJ Open 6: 1-8.

34. Nduati NJ, Simon K, Eva N, Lawrence M (2016) Factors associated with glycemic control among type 2 diabetes patients attending Mathari National Teaching Hospital, Nairobi Kenya. J Endocrinol diabetes 3: 1-11.

35. Kakade A, Mohanty IR, Rai S (2018) Assessment of factors associated with poor glycemic control among patients with Type II Diabetes mellitus. Integgrative Obes Diabetes 4: 1-6.

36. Radwan M, Elsous A, Al-Sharif H, Abu Mustafa A (2018) Glycemic control among primary care patients with type 2 diabetes mellitus in the Gaza Strip, Palestine. Ther Adv Endocrinol Metab 9: 3-14.

37. Musenge EM, Manankov A, Mudenda B, Michelo C (2014) Glycaemic control in diabetic patients in Zambia. Pan Afr Med J 19: 1-13.

38. Bayisa B, Bekele M (2017) Glycemic Control and Associated Factors among Type II Diabetic Patients on Chronic Follow up at Southwest Ethiopia. J Med Heal Sci 6: $13-20$

39. Fseha B (2017) Glycemic Control and it's Associated Factors in Type 2 Diabetic Patients in Suhul Hospital, Northwest Tigray, Ethiopia. J Diabetes Metab 8: 1-6.

40. Ufuoma C, Godwin Y, Kester Ad, Ngozi Jc (2016) Determinants of glycemic control among persons with type 2 diabetes mellitus in Niger Delta. Sahel Med J 19: 190.

41. Rajeshwar Y, Eticha T, Mul A, Gebretsadik H, Kahsay G, et al. (2016) Factors Associated with Poor Glycemic Control in Type 2 Diabetic Patients Investigated at Ayder Referral Hospital, Mekelle, Ethiopia. IJPPR Hum 6: 160171.

42. Nemeh A A-A, Yousef SK, Aysha MA (2011) Glycemic Control and Its Determinants among Patients with type 2 Diabetes Mellitus Attending a Teaching Hospital. J Diabetes Metab 2: 129.

43. Sazlina SG, Mastura I, Cheong AT, Bujang Mohamad A, Jamaiyah H, et al. (2015) Predictors of poor glycaemic control in older patients with type 2 diabetes mellitus. Singapore Med J 56: 284-290.

Copyright: C2020 Alemayehu Digssie. This is an open-access article distributed under the terms of the Creative Commons Attribution License, which permits unrestricted use, distribution, and reproduction in any medium, provided the original author and source are credited. 